\title{
Additive antitumour effect of D-allose in combination with cisplatin in non-small cell lung cancer cells
}

\author{
NOBUHIRO KANAJI ${ }^{1}$, KAZUYO KAMITORI ${ }^{2}$, AKRAM HOSSAIN ${ }^{2}$, CHISATO NOGUCHI $^{2}$, \\ AYAKO KATAGI $^{2}$, NORIMITSU KADOWAKI ${ }^{1}$ and MASAAKI TOKUDA ${ }^{2}$ \\ Departments of ${ }^{1}$ Internal Medicine, Division of Hematology, Rheumatology and Respiratory Medicine \\ and ${ }^{2}$ Cell Physiology, Faculty of Medicine, Kagawa University, Kagawa 761-0793, Japan
}

Received June 6, 2017; Accepted November 28, 2017

DOI: $10.3892 /$ or.2018.6192

\begin{abstract}
D-allose is a rare sugar which has been shown to have growth inhibitory effects in several kinds of malignancies. However, the effect of D-allose on lung cancer progression has not been previously studied. To investigate the antitumour effect of D-allose in lung cancer cells and its mechanism, human non-small cell lung cancer (NSCLC) cell lines (squamous cell carcinomas: EBC1 and VMRC-LCD; adenocarcinomas: A549, HI1017, RERF-LC-A1 and NCI-H1975) were treated with D-allose $(50 \mathrm{mM})$ with or without cisplatin $(5 \mu \mathrm{M})$. D-allose inhibited cell growth, particularly in EBC1 and VMRC-LCD cells. In combination with cisplatin, D-allose had a synergistic growth inhibitory effect. D-allose increased the expression of thioredoxin interacting protein (TXNIP) at mRNA and protein levels. D-allose decreased the proportion of cells in G1 phase and increased those in $\mathrm{S}$ and $\mathrm{G} 2 / \mathrm{M}$ phases. For in vivo experiments, EBC1 cells were inoculated into BALB/c- $n u$ mice. After tumourigenesis, D-allose and cisplatin were injected. In this mouse xenograft model, additional treatment with D-allose showed a significantly greater tumour inhibitory effect compared with cisplatin alone, accompanied by lower Ki-67 and higher TXNIP expression. In conclusion, D-allose inhibited NSCLC cell proliferation in vitro and tumour progression in vivo. In combination with cisplatin, D-allose had an additional antitumour effect. Specifically, increased TXNIP expression and subsequent $\mathrm{G} 2 / \mathrm{M}$ arrest play a role in D-allose-mediated antitumour effects in NSCLC.
\end{abstract}

Correspondence to: Dr Nobuhiro Kanaji, Department of Internal Medicine, Division of Hematology, Rheumatology and Respiratory Medicine, Faculty of Medicine, Kagawa University, 1750-1 Ikenobe, Miki-cho, Kita-gun, Kagawa 761-0793, Japan

E-mail: kanaji@med.kagawa-u.ac.jp

Abbreviations: NSCLC, non-small cell lung cancer; TXNIP, thioredoxin interacting protein

Key words: D-allose, lung cancer, proliferation, rare sugar, xenograft, mouse, cisplatin

\section{Introduction}

D-allose is a rare sugar that is found only in very small quantities in nature. However, the discovery of D-tagatose 3-epimerase, an enzyme that can convert D-fructose to $\mathrm{D}$-allulose (psicose) enabled the bioproduction on a large scale of all rare sugars including D-allose as shown by the ring form structure named 'Izumoring' $(1,2)$.

Recent studies have shown that D-allose has growth inhibitory effects in several kinds of malignancies including hepatocellular carcinoma, prostate, ovarian, and head and neck cancers, and leukaemia (3-9). However, the effect of D-allose on lung cancer progression has not been studied.

Thioredoxin, a small molecular weight protein, is a potent protein disulphide oxidoreductase that functions as a potent antioxidant $(10,11)$. Protein disulphide targets for reduction by thioredoxin include many transcription factors involved in cell activation and proliferation such as $\mathrm{p} 53$, nuclear factor- $\kappa \mathrm{B}$, and AP-1 $(10,11)$. Some studies have shown that the expression of thioredoxin is associated with growth and differentiation of non-small cell lung cancer (NSCLC) (12-15). Serum thioredoxin levels were higher in NSCLC patients than in controls (15). The expression of thioredoxin is also associated with lymph node metastasis and poor prognosis in patients with operable NSCLC (10).

Thioredoxin interacting protein (TXNIP), also known as vitamin $\mathrm{D}_{3}$ upregulated protein 1 (16) or thioredoxin-binding protein-2 (17), interacts with thioredoxin and serves as a negative regulator of its biological function (17). TXNIP mediates cell cycle arrest and acts as a tumour suppressor $(18,19)$. Notably, TXNIP deficiency initiated hepatocellular carcinogenesis in transgenic mice (20). In addition, recent reports have shown that D-allose stimulates the expression of TXNIP in several kinds of malignancy $(7,9,21,22)$.

Based on this background, we investigated the antitumour effect of D-allose in lung cancer cells in combination with cisplatin, one of the most readily available anticancer drugs for lung cancer, and its effect on TXNIP expression.

\section{Materials and methods}

Reagents. Sugars used in this study, including D-glucose, D-allose, and D-allulose (also called D-psicose), were supplied 
by the Rare Sugars Research Centre, Kagawa University (Kagawa, Japan). Antibodies used were anti- $\beta$-actin (\#A2228; Sigma-Aldrich, St. Louis, MO, USA), anti-thioredoxin (\#2429; Cell Signaling Technology, Inc., Beverly, MA, USA) and anti-TXNIP (\#K0205-3; MBL, Nagoya, Japan, and \#HPA031085; Sigma-Aldrich). Cisplatin was purchased from Wako Pure Chemical Industries, Ltd. (Kanagawa, Japan).

Cell culture. Human NSCLC cell lines (squamous cell carcinomas: EBC1 and VMRC-LCD; adenocarcinomas: A549, HI1017 and RERF-LC-A1) were obtained from the Japan Cancer Research Bank (Tokyo, Japan). NCI-H1975 (adenocarcinoma) cells were obtained from American Culture Collection (Manassas, VA, USA). NSCLC cells were cultured in RPMI-1640 supplemented with $10 \%$ foetal bovine serum (FBS).

Lung cancer cell viability. Lung cancer cell viability was assessed by WST-1 assay. Briefly, cells were incubated in RPMI-1640 with 10\% FBS and 10\% WST-1 reagent (Roche Applied Science, Mannheim, Germany). After incubation for $4 \mathrm{~h}, 100 \mu \mathrm{l}$ of sample was transferred to a 96 -well plate and the absorbance at $450 \mathrm{~nm}$ was measured with a microplate reader (iMark $^{\mathrm{TM}}$; Bio-Rad, Hercules, CA, USA). All samples were assessed in at least triplicate.

Animals and xenotransplantation. BALB/c-nu mice female were purchased from Charles River Laboratories Japan, Inc. (Yokohama, Japan) and maintained in the Division of Animal Experiments, Life Science Research Center, Kagawa University according to the Institutional Regulations for Animal Experiments. The protocols for the animal experiments were approved by the Animal Care and Use Committee for Kagawa University (the ethical permit no. 15161). Briefly, $10^{6}$ EBC1 cells were subcutaneously inoculated into 48 six-week-old mice. Two weeks later, tumourigenesis was observed. Subsequently, cisplatin $(3 \mathrm{mg} / \mathrm{kg}, 100 \mu \mathrm{l}$ in PBS) was injected intraperitoneally for 3 weeks (once a week) and D-allose (500 mM, $100 \mu \mathrm{l}$ in PBS) was injected around the tumour for 3 weeks (five days per week). Only PBS was injected as controls. Twelve mice were assessed in each group. Tumour sizes were measured every week with a calliper. The tumour volume (TV) was calculated using the formula $\mathrm{TV}=1 / 2 \times \mathrm{A} \times \mathrm{B} 2$ (where $\mathrm{A}=$ length in millimetres and $\mathrm{B}=$ width in millimetres) in accordance with previous studies (23). Mice were monitored for up to 8 weeks after inoculation then euthanized.

Histology and immunohistochemistry. The engrafted tumours were fixed and tissue sections were immunohistochemically examined using Vectastain ABC rabbit IgG kit (Vector Laboratories, Burlingame CA, USA) using an anti-TXNIP antibody (\#HPA031085; Sigma-Aldrich). Immunostaining for Ki-67 was performed at Shikoku Cytopathological Laboratory (Kagawa, Japan) using an anti-Ki-67 antibody (Dako, Glostrup, Germany). For subsequent procedures, a BOND automatic detection system (Leica Biosystems, Bannockburn, IL, USA) was used. Five samples per condition were evaluated, and the percentage of tumour cells expressing TXNIP or Ki-67 was assessed.
Western blotting. After sugar treatment for three days, cells were scraped into lysis buffer (20 mM Tris-HCl, pH 7.5, $150 \mathrm{mM}$ $\mathrm{NaCl}, 5 \mathrm{mM}$ EDTA, $0.5 \%$ Triton $\mathrm{X}-100$, and $0.5 \% \mathrm{NP} 40$ ) with protease inhibitors (Sigma-Aldrich) and treated with sonication. Samples were centrifuged for $5 \mathrm{~min}$ at $14,000 \mathrm{rpm}$ and the supernatants were collected. For western blot analysis, $20 \mu \mathrm{g}$ proteins were separated in $10 \%$ SDS-polyacrylamide gels, transferred to nitrocellulose membranes, and blocked with $5 \%(\mathrm{w} / \mathrm{v})$ non-fat dried milk in TTBS. The membrane was incubated with anti-TXNIP (MBL, 1:2,000), anti-thioredoxin $(1: 1,000)$ or anti- $\beta$-actin $(1: 5,000)$ antibodies, and then incubated with a horseradish peroxidase-conjugated anti-mouse IgG (Cell Signalling Technology, Inc.). Signals were detected with Immobilon Western Chemiluminescent HRP Substrate (Millipore, Billerica, MA, USA).

Real-time quantitative PCR. Cells were cultured in a $60-\mathrm{mm}$ dish and $50 \mathrm{mM}$ of various sugars were added to the medium and further incubated for three days. Total RNA was purified with an RNeasy Mini kit (Qiagen, Hilden, Germany), and used to synthesize cDNAs with an Omniscript RT kit (Qiagen) and random hexamers (Takara Bio Inc., Shiga, Japan). Real-time quantitative PCR was carried out using Probe qPCR mix (Takara Bio Inc.), TaqMan gene expression assay primers (Applied Biosystems, Waltham, MA, USA), and a 7300 real-time PCR system (Applied Biosystems). Primers used were purchased from Applied Biosystems (TaqMan primers; TXNIP: Hs01006897_g1, thioredoxin: Hs01555214_ g1, GAPDH: Hs02758991_g1). PCR amplifications comprised 40 cycles of denaturation at $95^{\circ} \mathrm{C}$ for $10 \mathrm{sec}$, annealing and elongation at $60^{\circ} \mathrm{C}$ for $30 \mathrm{sec}$. Each reaction was performed in duplicate. GAPDH gene expression was used as an internal control and the threshold value $(\mathrm{Ct})$ for each sample was used to determine the expression level of the gene.

Profiling of DNA content by flow cytometry. Profiling of DNA content was performed as previously reported (24). Briefly, cells were treated with sugars $(50 \mathrm{mM})$ or cisplatin $(5 \mu \mathrm{M})$ for $24 \mathrm{~h}$ and then fixed with cold $70 \%$ ethanol in PBS for $30 \mathrm{~min}$ at $4^{\circ} \mathrm{C}$. Cells were then pelleted by centrifugation and resuspended in the staining solution (50 $\mu \mathrm{g}$ propidium iodide, $100 \mu \mathrm{g}$ RNase A in $1 \mathrm{ml}$ PBS). After 1 -h incubation at $4^{\circ} \mathrm{C}$, the DNA content profile was assessed by flow cytometry.

Statistical analysis. Each experiment was repeated at least three times. Student's t-test was used to compare data between two groups. Data are expressed as the means $\pm \mathrm{SE}$. P-values of $<0.05$ were considered as statistically significant. All statistical analyses were conducted using Excel 2013 (Microsoft Corp., Redmond, WA, USA).

\section{Results}

D-allose inhibits the proliferation of lung cancer cells. NSCLC cell lines were cultured in regular medium with either D-glucose, D-allose, or D-allulose. The proliferation of EBC1 cells, a squamous cell lung cancer cell line, was inhibited by D-allose in a dose- and time-dependent manner (Fig. 1A and B). Similarly, proliferation of another squamous cell lung cancer cell line, VMRC-LCD, was also inhibited by 
A

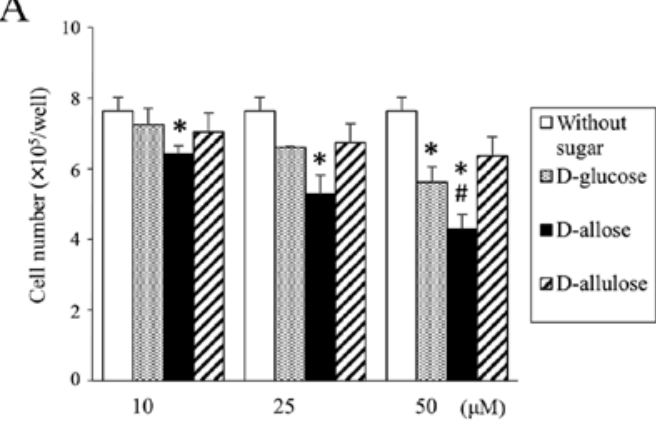

B

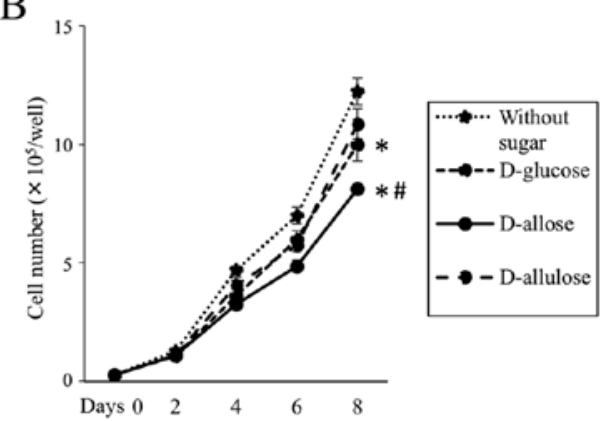

$\mathrm{C}$

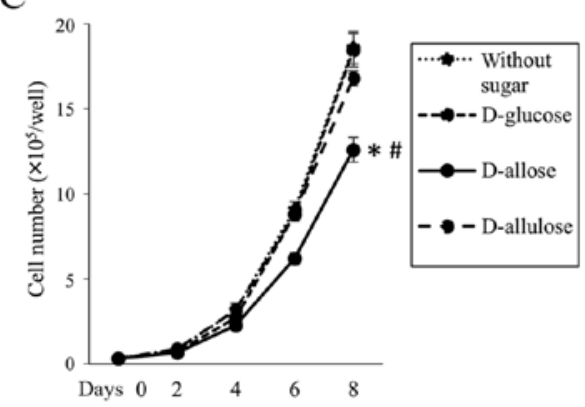

D

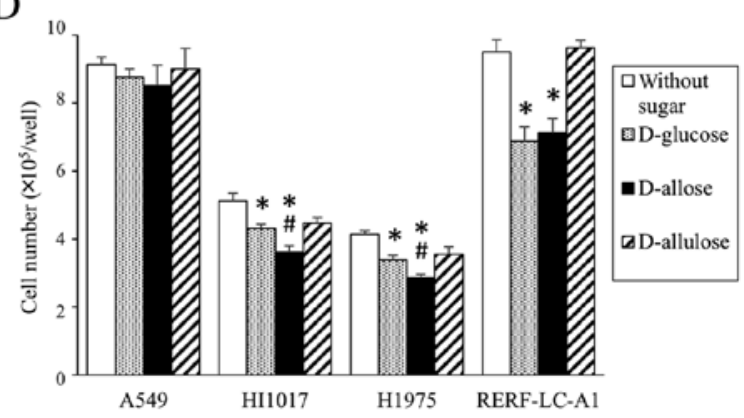

Figure 1. Effect of sugars on proliferation of lung cancer cells. Lung cancer cell lines were cultured in RPMI-1640 with either D-glucose, D-allose, or D-allulose. The medium was replaced every two days, and cell numbers were counted. (A) EBC1 cells were cultured for six days with various concentrations of sugars and cell numbers were counted. (B) Time course of EBC1 cell proliferation with 50 mM of sugars. (C) Time course of VMRC-LCD cell proliferation with $50 \mathrm{mM}$ of sugars. (D) Lung adenocarcinoma cell lines (A549, HI1017, H1975 and RERF-LC-A1 cells) were cultured with 50 mM of sugars for six days and cell numbers were counted. ${ }^{*} \mathrm{P}<0.01$ compared with those cultured without sugars and ${ }^{\#} \mathrm{P}<0.01$ compared with those cultured with $\mathrm{D}$-glucose.

D-allose (Fig. 1C). However, the cell growth inhibitory effect of D-allose was very small or no difference was observed compared with that of D-glucose in other cell lines tested (adenocarcinomas: A549, HI1017, H1975 and RERF-LC-A1 cells, Fig. 1D). Cisplatin inhibited cell proliferation (viability) in both EBC1 and VMRC-LCD cell lines (Fig. 2). In combination with D-allose, but not D-glucose or D-allulose, cell proliferation (viability) was further inhibited (Fig. 2).

$D$-allose stimulates the expression of TXNIP and modifies the DNA content profile. The expression of TXNIP increased in response to D-allose, but not to other sugars, in both $\mathrm{EBC1}$ and VMRC-LCD cells (Fig. 3). This was confirmed by both western blotting (Fig. 3A) and real-time PCR (Fig. 3B and C). Although TXNIP mRNA expression was also increased by cisplatin in EBC1 cells, this was not statistically significant (Fig. 3B). On the other hand, no obvious changes in expressions of thioredoxin were observed in response to D-allose (Fig. 3D-F). To investigate modulation of cell cycles, DNA content profiling was assessed (Fig. 4). After D-allose treatment, the percentage of cells in G1 phase of the cell cycle moderately decreased, while that in $\mathrm{S}$ and $\mathrm{G} 2 / \mathrm{M}$ phases increased. In contrast, cisplatin induced significant mid-S-phase accumulation and reduction in $\mathrm{G} 2 / \mathrm{M}$ phases.

$D$-allose inhibits the tumour progression in mouse xenografts. $\mathrm{EBCl}$ cells were subcutaneously inoculated into BALB/c-nu mice and after tumour development, D-allose and cisplatin were injected as described in Materials and methods. Both D-allose and cisplatin inhibited tumour progression compared
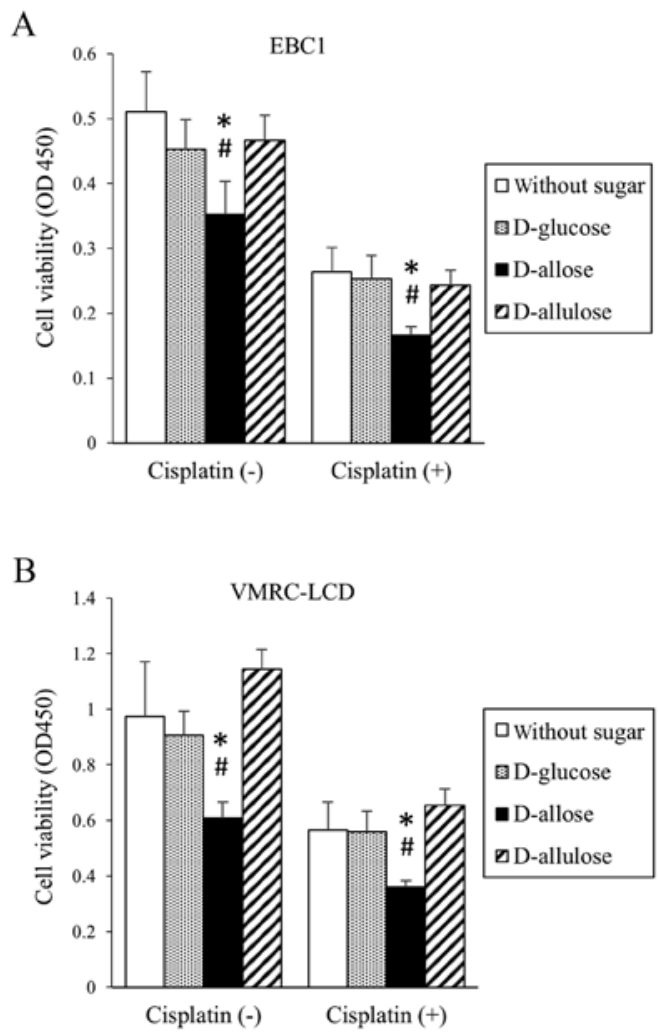

Figure 2. Combination of D-allose and cisplatin on cell proliferation. (A) EBC1 and (B) VMRC-LCD cells were cultured with sugars (50 mM) and/or cisplatin $(5 \mu \mathrm{M})$. After three days, cell proliferation (viability) was assessed by WST-1 assay. ${ }^{*} \mathrm{P}<0.01$ compared with those cultured without sugars and ${ }^{\#} \mathrm{P}<0.01$ compared with those cultured with $\mathrm{D}$-glucose at the same cisplatin status. 
A
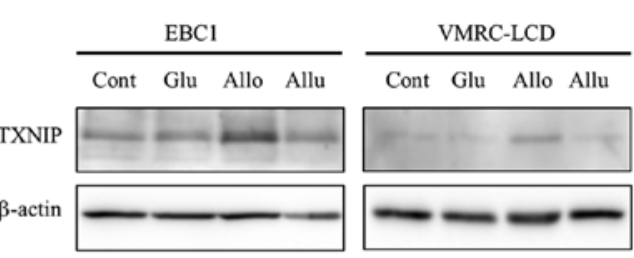

B

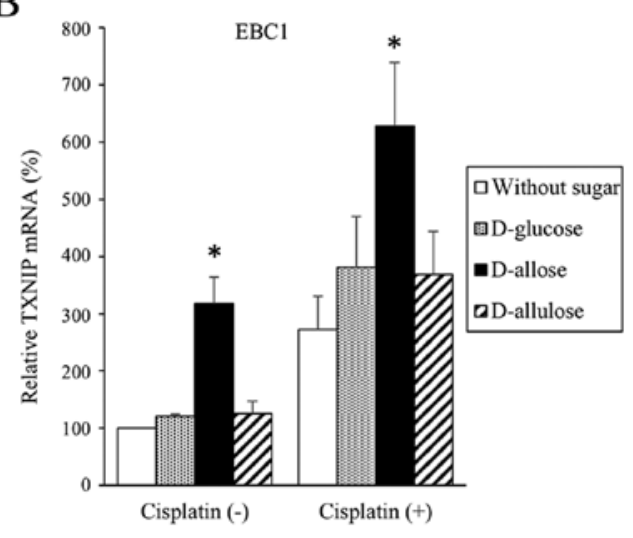

D

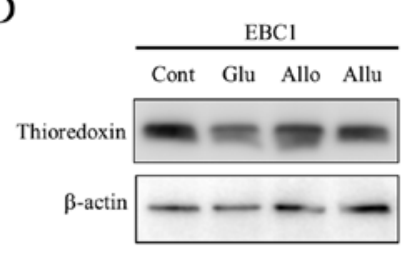

E

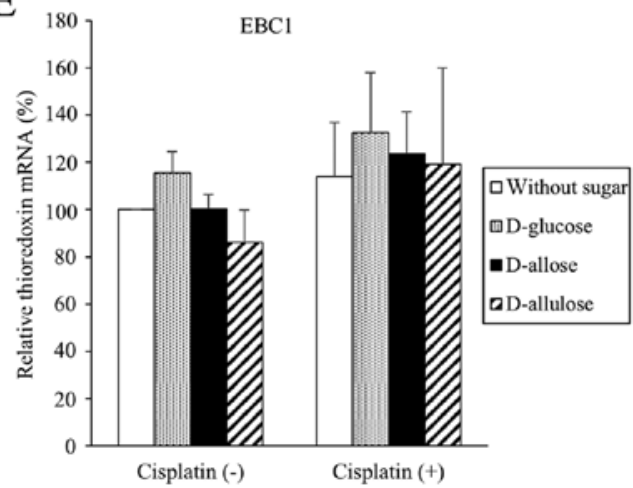

$\mathrm{C}$

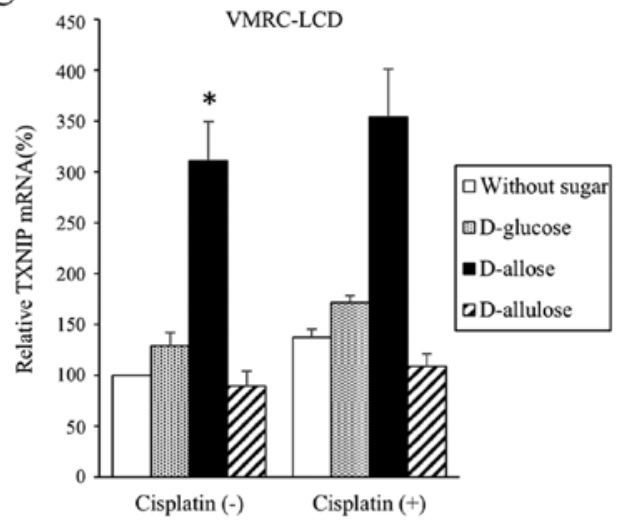

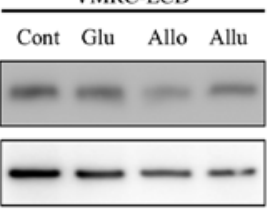

F

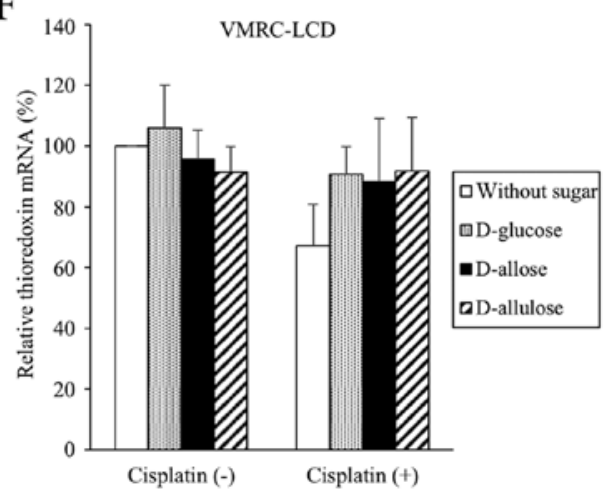

Figure 3. Expression of TXNIP and thioredoxin in response to D-allose. Cells were treated with sugars (50 mM) for three days and TXNIP (A-C) and thioredoxin (D-F) expression was assessed. (A and D) Western blotting. Cont, without any sugar; Glu, D-glucose; Allo, D-allose; and Allu, D-allulose. (B, C, E and F) Real-time PCR [(B and E) EBC1; and (C and F) VMRC-LCD cells]. Data are expressed as means of 5 (EBC1) or 3 (VMRC -LCD) separate experiments. " $\mathrm{P}<0.05$ compared with those cultured without sugars. TXNIP, thioredoxin interacting protein.

with the control (PBS alone) (Fig. 5A). Combined treatment with $\mathrm{D}$-allose and cisplatin resulted in a significant reduction in tumour volumes compared with cisplatin alone (Fig. 5A). No obvious side effect such as body weight loss was observed in the D-allose group, while treatment with cisplatin resulted in body weight loss slightly but significantly (Fig. 5B). Consistent with reduced tumour volumes, the $\mathrm{Ki}-67$ index was lower in the $\mathrm{D}$-allose plus cisplatin group compared with cisplatin alone (Fig. 5C). Similar to the in vitro experiments, higher levels of TXNIP expression were observed in the D-allose plus cisplatin group compared with cisplatin alone (Fig. 5D).

\section{Discussion}

In the present study, D-allose inhibited NSCLC cell proliferation and tumour progression. Supplementary D-allose treatment resulted in stronger antitumour effect than cisplatin 
A

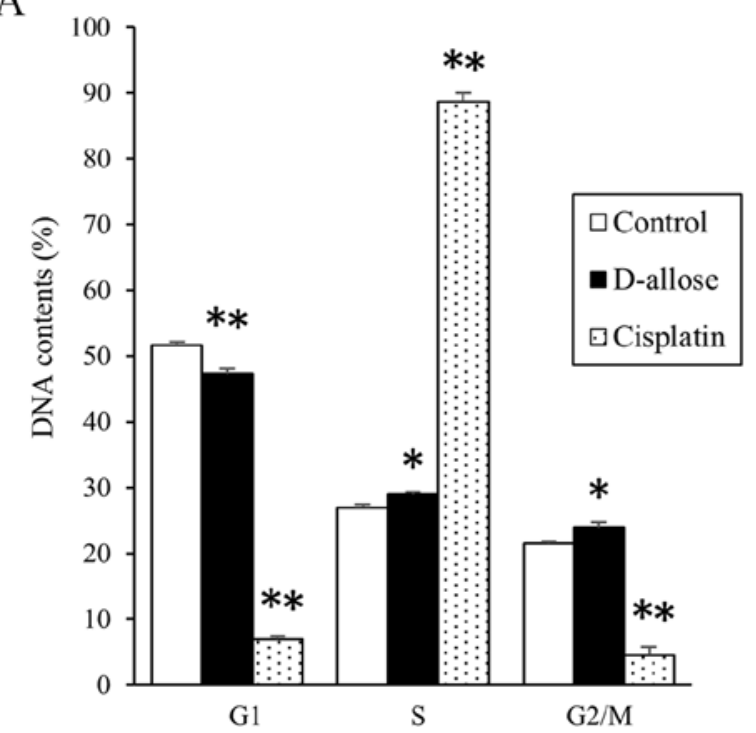

$\mathrm{B}$

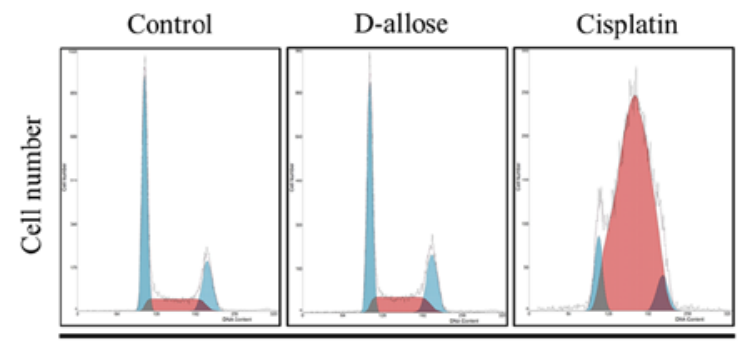

DNA content

Figure 4. Profiling of DNA contents. EBC1 cells were treated with sugars $(50 \mathrm{mM})$ or cisplatin $(5 \mu \mathrm{M})$ for $24 \mathrm{~h}$. Cells were harvested and the DNA content profile was assessed by flow cytometry. (A) Values are the means of three separate experiments. ${ }^{*} \mathrm{P}<0.05,{ }^{* *} \mathrm{P}<0.01$ compared with control. (B) Representative histograms for each condition.

A

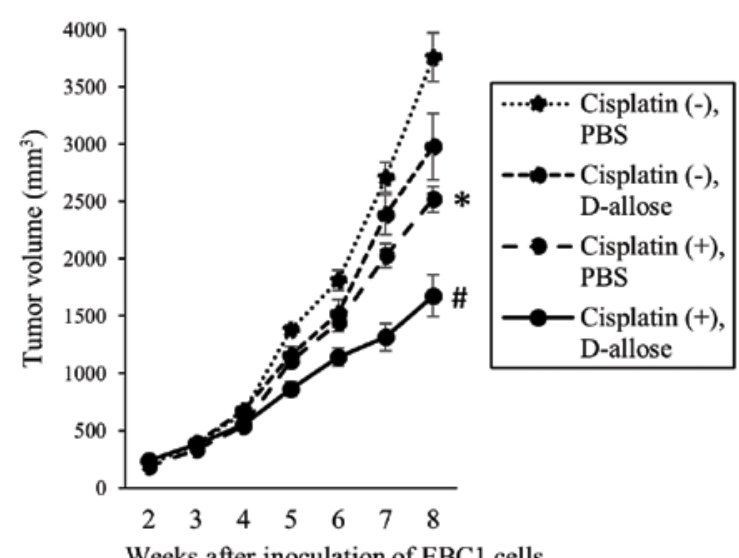

Weeks after inoculation of $\mathrm{EBCl}$ cells

C

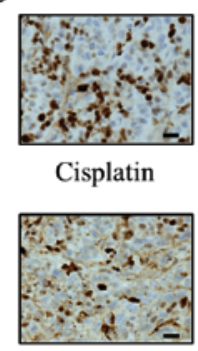

Cisplatin

+ D-allose

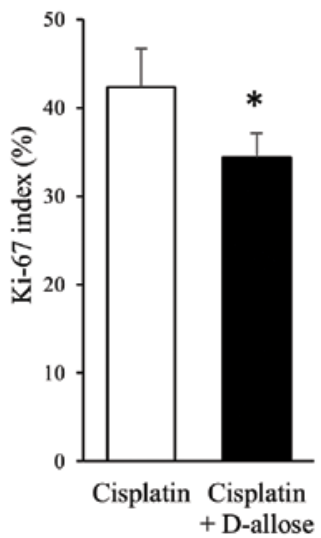

D
B

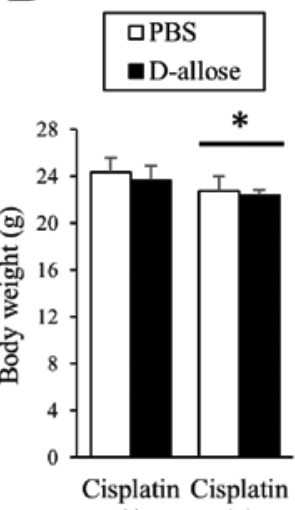

$(-)$

(+)
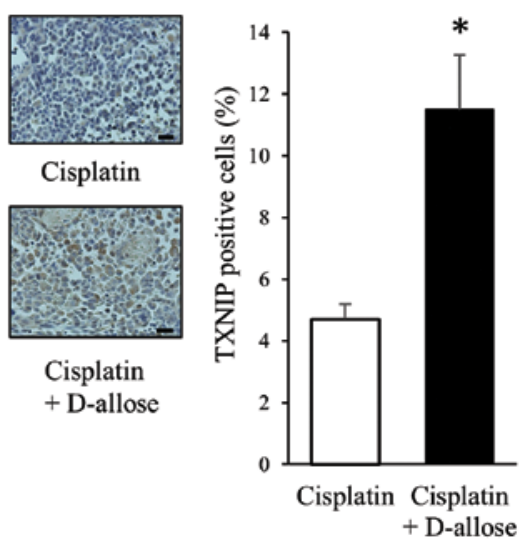

Figure 5. Tumour progression in mouse xenografts. One million EBC1 cells were inoculated subcutaneously per BALB/c-nu mouse. Two weeks after inoculation, tumourigenesis was observed. Subsequently, cisplatin $(3 \mathrm{mg} / \mathrm{kg}$ ) was injected intraperitoneally for 3 weeks (once a week) and D-allose (500 mM) was injected around the tumour for 3 weeks (five days per week). Tumour size was measured up to 8 weeks after inoculation of cells, and then mice were euthanized. Twelve tumours (mice) were assessed in each group. (A) Time course of the tumour size. ${ }^{\text {}} \mathrm{P}<0.01$ compared with conditions without cisplatin and ${ }^{\#} \mathrm{P}<0.05$ compared with conditions with cisplatin only. (B) Body weight of mice at 8 weeks. " $\mathrm{P}<0.05$ compared with the group without cisplatin. (C) Ki-67 index in tumour tissues. Five tumours (mice) were assessed per group. ${ }^{*} \mathrm{P}<0.05$ compared with the group with cisplatin only. Scale bars, $50 \mu \mathrm{m}$. (D) Immunostaining for TXNIP in tumour tissues. "P $<0.05$ compared with the group with cisplatin only. Scale bars, $50 \mu \mathrm{m}$. TXNIP, thioredoxin interacting protein. 
alone. D-allose worked differently from cisplatin on NSCLC cells and markedly stimulated TXNIP expression, a tumour suppressor gene product, to inhibit cell proliferation, which might be a mechanism of the antitumour effect.

The growth inhibitory effect of D-allose was more significant in squamous cell carcinoma (EBC1 and VMRC-LCD) than in adenocarcinoma (A549, HI1017, H1975 and RERF-LC-A1) cell lines. Thus, there might be a difference in the response to D-allose between squamous cell carcinoma and adenocarcinoma. In the last two decades, several novel therapeutic options have been newly developed for lung adenocarcinoma, including pemetrexed (an anticancer drug), bevacizumab (a monoclonal antibody targeting vascular endothelial growth factor), and several tyrosine kinase inhibitors for epidermal growth factor receptor and anaplastic lymphoma kinase. These drugs are usually unavailable for squamous cell carcinoma because of their ineffectiveness and adverse events. Although the anticancer effect of D-allose itself might be small for NSCLC, it demonstrates additional potential in combination with cytotoxic agents such as cisplatin. Thus, D-allose might be a new supplemental treatment for lung cancer, particularly for squamous cell carcinoma.

Some evidence has shown that antioxidants protect and stimulate the growth of established tumours (25-27). A large epidemiologic study has shown a higher incidence of lung cancer in men who received $\beta$-carotene, a representative antioxidant, than in those who did not (25). A review report concluded that the intake of supplemental antioxidants during chemotherapy and radiotherapy should be discouraged because of the possibility of tumour protection and reduced survival (26). In addition, the antioxidants $\mathrm{N}$-acetylcysteine and vitamin $\mathrm{E}$ accelerated lung cancer progression and reduced survival in mouse models (27). These findings suggest that antioxidants protect tumour cells as well as healthy cells from oxidative damage and accelerate cell proliferation of early cancers or tumourigenesis of precancerous lesions (27). In a view of the redox status, D-allose stimulates TXNIP, which might result in increased antitumour activity in NSCLC.

Several concrete mechanisms for the antitumour effect of D-allose have been reported. First, D-allose modulates cell cycle regulatory proteins and induces $\mathrm{G} 2 / \mathrm{M}$ cell cycle arrest (7). Consistent with this report, D-allose treatment resulted in accumulation in $\mathrm{G} 2 / \mathrm{M}$ phases in the present study. Low $\mathrm{Ki}-67$ index in the in vivo experiment is also consistent with this G2/M cell cycle arrest. Another study reported that D-allose induces upregulation of TXNIP and subsequent G1 cell cycle arrest (21). Thioredoxin is an important regulator of the cell cycle in the G1 phase via cyclin D1 transcription and the ERK/AP-1 signalling pathways (28). Regarding the growth inhibitory effect of D-allose, it has been reported that the nuclear localization and stabilization of $\mathrm{p} 27^{\mathrm{kip} 1}$, increases in cyclin-dependent kinase (CDK) 2 and CDK inhibitor 2B, and decrease in FK506 binding protein 12-rapamycinassociated protein 1 have roles (21). Second, upregulation of TXNIP and inhibition of thioredoxin by D-allose can induce the generation of reactive oxygen species, resulting in DNA damage in cells and antitumour effects (7). Third, apoptosis could be induced by D-allose (7), however, apoptosis may not appear in all types of cells (3). Fourth, D-allose can inhibit glucose transporter expression and glucose uptake in several human cancer cell lines (9). Some of the above mechanisms of the antitumour effect of D-allose could be associated with regulating expression of thioredoxin and TXNIP, that is, redox status in the broader sense.

In cell cycle analyses, cisplatin significantly induced mid-S-phase accumulation, which is consistent with a previous report (29). Because the modulation pattern in cell cycles is different between cisplatin and D-allose, the combination of these two agents may have additional antitumour potential compared with each agent by itself. Cisplatin showed a tendency to increase the expression of TXNIP although no statistical significance was observed. In this regard, several studies have investigated the effect of anticancer drugs on the expression of TXNIP (3,7,30). 5-Fluorouracil stimulated TXNIP expression in hepatocellular carcinoma and colon cancer cells, suggesting the mechanism of cytotoxicity of this drug $(3,30)$. In contrast, docetaxel had no effect on TXNIP expression in head and neck cancer cells (7). Thus, the anticancer drugs seem to vary in their influence on TXNIP expression depending upon their mechanism of action.

Several studies have reported the clinical significance of thioredoxin and TXNIP in NSCLC from other viewpoints. Thioredoxin takes part in the activation of transcription factors and regulates differentiation as well as cell growth (14). In high-grade tumours, thioredoxin expression is diminished, suggesting loss of redox regulation in tumours with low differentiation (14). In addition, it has been reported that patients with high TXNIP expression demonstrated a significantly shorter progression-free survival compared with those with low TXNIP expression (31). The expression of TXNIP could also be affected by many factors including tumour environment (31). In the present study, no obvious change in thioredoxin expression was observed in response to D-allose. In this regard, thioredoxin expression itself may not always change because TXNIP binds thioredoxin, and thioredoxin activity may be more important. The clinical significance of the expression and activity of thioredoxin and TXNIP in patients with NSCLC should be investigated in greater detail.

Because most cell types express glucose transporters, D-allose may affect cell growth in normal cells as well as cancer cells. However, interestingly, it has been reported that no growth inhibitory or cytotoxic effects of D-allose were observed in normal hepatocytes (21). In addition, D-allose inhibited GLUT1 expression (9). In the present study, D-allose had no obvious unfavourable side effect in the mouse xenograft model, which is an advantage in clinical use. We also injected D-allose subcutaneously directly around the developed tumour. However, it is technically difficult to inject around tumours developed inside the lung. For the clinical use of D-allose, another drug delivery route such as oral ingestion or intravenous administration should be developed.

In conclusion, D-allose inhibited NSCLC cell proliferation in vitro and tumour progression in vivo. In combination with cisplatin, D-allose had an additive antitumour effect. Specifically, increased TXNIP expression and subsequent $\mathrm{G} 2 / \mathrm{M}$ arrest play a role in D-allose-mediated antitumour effects in NSCLC. 


\section{Acknowledgements}

The authors would like to thank Ms. Takimi Tamaki for her support. This study was supported by the Rare Sugar Research grant funded by Kagawa Prefecture.

\section{References}

1. Izumori K: Bioproduction strategies for rare hexose sugars. Naturwissenschaften 89: 120-124, 2002.

2. Granström TB, Takata G, Tokuda M and Izumori K: Izumoring: A novel and complete strategy for bioproduction of rare sugars. J Biosci Bioeng 97: 89-94, 2004.

3. Yamaguchi F, Kamitori K, Sanada K, Horii M, Dong Y, Sui L and Tokuda M: Rare sugar D-allose enhances anti-tumor effect of 5-fluorouracil on the human hepatocellular carcinoma cell line HuH-7. J Biosci Bioeng 106: 248-252, 2008.

4. Jeong RU, Lim S, Kim MO and Moon MH: Effect of D-allose on prostate cancer cell lines: Phospholipid profiling by nanoflow liquid chromatography-tandem mass spectrometry. Anal Bioanal Chem 401: 689-698, 2011.

5. Sui L, Dong Y, Watanabe Y, Yamaguchi F, Hatano N, Izumori K and Tokuda M: Growth inhibitory effect of D-allose on human ovarian carcinoma cells in vitro. Anticancer Res 25: 2639-2644, 2005.

6. Mitani T, Hoshikawa H, Mori T, Hosokawa T, Tsukamoto I, Yamaguchi F, Kamitori K, Tokuda M and Mori N: Growth inhibition of head and neck carcinomas by D-allose. Head Neck 31 : 1049-1055, 2009.

7. Indo K, Hoshikawa H, Kamitori K, Yamaguchi F, Mori T, Tokuda $\mathrm{M}$ and Mori $\mathrm{N}$ : Effects of D-allose in combination with docetaxel in human head and neck cancer cells. Int J Oncol 45: 2044-2050, 2014.

8. Hirata Y, Saito M, Tsukamoto I, Yamaguchi F, Sui L, Kamitori K, Dong Y, Uehara E, Konishi R, Janjua N, et al: Analysis of the inhibitory mechanism of D-allose on MOLT-4F leukemia cell proliferation. J Biosci Bioeng 107: 562-568, 2009.

9. Noguchi C, Kamitori K, Hossain A, Hoshikawa H, Katagi A, Dong Y, Sui L, Tokuda M and Yamaguchi F: D-allose inhibits cancer cell growth by reducing GLUT1 expression. Tohoku J Exp Med 238: 131-141, 2016.

10. Kakolyris S, Giatromanolaki A, Koukourakis M, Powis G, Souglakos J, Sivridis E, Georgoulias V, Gatter KC and Harris AL: Thioredoxin expression is associated with lymph node status and prognosis in early operable non-small cell lung cancer. Clin Cancer Res 7: 3087-3091, 2001.

11. Nordberg J and Arnér ES: Reactive oxygen species, antioxidants, and the mammalian thioredoxin system. Free Radic Biol Med 31: $1287-1312,2001$

12. Ceccarelli J, Delfino L, Zappia E, Castellani P, Borghi M, Ferrini S, Tosetti F and Rubartelli A: The redox state of the lung cancer microenvironment depends on the levels of thioredoxin expressed by tumor cells and affects tumor progression and response to prooxidants. Int J Cancer 123: 1770-1778, 2008.

13. Fernandes AP, Capitanio A, Selenius M, Brodin O, Rundlöf AK and Björnstedt M: Expression profiles of thioredoxin family proteins in human lung cancer tissue: Correlation with proliferation and differentiation. Histopathology 55: 313-320, 2009.

14. Soini Y, Kahlos K, Näpänkangas U, Kaarteenaho-Wiik R, Säily M, Koistinen P, Pääakkö P, Holmgren A and Kinnula VL: Widespread expression of thioredoxin and thioredoxin reductase in non-small cell lung carcinoma. Clin Cancer Res 7: 1750-1757, 2001.

15. Fan J, Yu H, Lv Y and Yin L: Diagnostic and prognostic value of serum thioredoxin and DJ-1 in non-small cell lung carcinoma patients. Tumour Biol 37: 1949-1958, 2016.
16. Chen KS and DeLuca HF: Isolation and characterization of a novel cDNA from HL-60 cells treated with 1,25-dihydroxyvitamin D-3. Biochim Biophys Acta 1219: 26-32, 1994.

17. Nishiyama A, Matsui M, Iwata S, Hirota K, Masutani H, Nakamura H, Takagi Y, Sono H, Gon Y and Yodoi J: Identification of thioredoxin-binding protein-2/vitamin $\mathrm{D}(3)$ up-regulated protein 1 as a negative regulator of thioredoxin function and expression. J Biol Chem 274: 21645-21650, 1999.

18. Han SH, Jeon JH, Ju HR, Jung U, Kim KY, Yoo HS, Lee YH, Song KS, Hwang HM, Na YS, et al: VDUP1 upregulated by TGF-beta1 and 1,25-dihydroxyvitamin D3 inhibits tumor cell growth by blocking cell-cycle progression. Oncogene 22 : 4035-4046, 2003.

19. Jeon JH, Lee KN, Hwang CY, Kwon KS, You KH and Choi I: Tumor suppressor VDUP1 increases p27(kip1) stability by inhibiting JAB1. Cancer Res 65: 4485-4489, 2005.

20. Sheth SS, Bodnar JS, Ghazalpour A, Thipphavong CK, Tsutsumi S, Tward AD, Demant P, Kodama T, Aburatani H and Lusis AJ: Hepatocellular carcinoma in Txnip-deficient mice. Oncogene 25: 3528-3536, 2006.

21. Yamaguchi F, Takata M, Kamitori K, Nonaka M, Dong Y, Sui L and Tokuda M: Rare sugar D-allose induces specific up-regulation of TXNIP and subsequent G1 cell cycle arrest in hepatocellular carcinoma cells by stabilization of p27kip1. Int J Oncol 32: 377-385, 2008.

22. Hoshikawa H, Mori T and Mori N: In vitro and in vivo effects of D-allose: Up-regulation of thioredoxin-interacting protein in head and neck cancer cells. Ann Otol Rhinol Laryngol 119: 567-571, 2010.

23. Kanaji N, Tadokoro A, Susaki K, Yokokura S, Ohmichi K, Haba R, Watanabe N, Bandoh S, Ishii T, Dobashi H, et al: Higher susceptibility of NOD/LtSz-scid Il2rg (-/-) NSG mice to xenotransplanted lung cancer cell lines. Cancer Manag Res 6: 431-436, 2014

24. Kanaji N, Nelson A, Allen-Gipson DS, Sato T, Nakanishi M, Wang X, Li Y, Basma H, Michalski J, Farid M, et al: The p38 mitogen-activated protein kinases modulate endothelial cell survival and tissue repair. Inflamm Res 61: 233-244, 2012.

25. Alpha-Tocopherol, Beta Carotene Cancer Prevention Study Group: The effect of vitamin $\mathrm{E}$ and beta carotene on the incidence of lung cancer and other cancers in male smokers. N Engl J Med 330: 1029-1035, 1994.

26. Lawenda BD, Kelly KM, Ladas EJ, Sagar SM, Vickers A and Blumberg JB: Should supplemental antioxidant administration be avoided during chemotherapy and radiation therapy? J Natl Cancer Inst 100: 773-783, 2008.

27. Sayin VI, Ibrahim MX, Larsson E, Nilsson JA, Lindahl P and Bergo MO: Antioxidants accelerate lung cancer progression in mice. Sci Transl Med 6: 221ra15, 2014.

28. Mochizuki M, Kwon YW, Yodoi J and Masutani H: Thioredoxin regulates cell cycle via the ERK1/2-cyclin D1 pathway. Antioxid Redox Signal 11: 2957-2971, 2009.

29. Wagner JM and Karnitz LM: Cisplatin-induced DNA damage activates replication checkpoint signaling components that differentially affect tumor cell survival. Mol Pharmacol 76: 208-214, 2009

30. Takahashi Y, Nagata T, Ishii Y, Ikarashi M, Ishikawa K and Asai S: Up-regulation of vitamin D3 up-regulated protein 1 gene in response to 5-fluorouracil in colon carcinoma SW620. Oncol Rep 9: 75-79, 2002.

31. Li Y, Miao LY, Xiao YL, Huang M, Yu M, Meng K and Cai HR: Hypoxia induced high expression of thioredoxin interacting protein (TXNIP) in non-small cell lung cancer and its prognostic effect. Asian Pac J Cancer Prev 16: 2953-2958, 2015. 